\title{
Design of Asymmetric Parallel-Cascaded Micro-Ring Resonator Using Transfer Matrix and Signal Flow-Graph Method
}

\author{
Desain Asymmetric Parallel-Cascaded Micro-Ring \\ Resonator Menggunakan Metode Transfer Matrix dan \\ Signal Flow-Graph
}

\author{
Dadin Mahmudin *, Pamungkas Daud, and Yusuf Nur Wijayanto \\ Research Center for Electronics and Telecommunication, Indonesian Institute of Science (LIPI) \\ Jl. Sangkuriang, Kampus LIPI, Bandung 40135 Indonesia
}

\begin{abstract}
Abstrack
Asymmetric parallel-cascaded micro-ring resonator (APCMR) is proposed. The proposed device is composed of two or more micro-ring-resonators with different diameter. The proposed device is designed using transfer matrix combined with signal flow graph methods. The designed device with crosstalk less than and equal $-10 \mathrm{~dB}$ can be obtained by setting coupling coefficient. The proposed device can be used for optical filters and sensors.
\end{abstract}

Keywords: asymmetric parallel-cascaded micro-ring-resonator (APCMR), optical filter, transfer matrix, signal flow-graph.

\begin{abstract}
Abstrak
Telah didesain optimasi dari asymmetric parallel-cascaded micro-ring resonator. Devais yang diusulkan terdiri dari dua atau lebih micro-ring-resonator dengan diameter yang berbeda. Devais didesain dengan menggunakan metode transfer matrix yang dikombinasikan dengan metode signal flow graph. Devais yang dirancang dapat menghasilkan crosstalk -10 dB atau lebih rendah dengan mengubah koefisien kopling. Perangkat yang diusulkan dapat digunakan untuk filter optik dan sensor.
\end{abstract}

Kata kunci: asymmetric parallel-cascaded micro-ring resonator, filter optik, transfer matrix, signal flow-graph.

\section{INTRODUCTION}

In order to meet demand of large bandwidth in the optical fiber backbone network, the multiplexing technique used must be able to produce information with the speed of giga-bit/second (Gbit/s) and even terra-bit/second (Tbit/s). In general, WDM multiplexing is a technique that is useful to increase the speed of information and bandwidth by merging multiple optical signals over the same fiber optic cable, in which the signals coming from different optical sources with different wavelengths. Each wavelength can have the speed of information and different formats [1].

Filter has becoming an important element for wavelength-division-multiplexing (WDM) system in recent years and micro-ring resonator (MRR) is a type of optical filter potential for use in Dense-WDM (DWDM) networks. In DWDM networks, MRR can be used as an optical add/drop multiplexer (OADM) and multiplexer [2]. In addition, as a kind of filter-based optical waveguide, MRR can be designed and fabricated in a variety of structures and sizes. The MRR

\footnotetext{
* Corresponding Author

Email: dadin@ppet.lipi.go.id

Received: May 28, 2013; Revised: June 7, 2013

Accepted: June 28, 2013

Published: June 30, 2013

(C) 2013 PPET - LIPI

doi : 10.14203/jet.v13.28-32
}

can be adopted for single-micro-ring resonator (SMR), series-coupled-micro-ring resonator (SCMR), and parallel-coupled-micro-ring resonator (PCMR). However, they still have disadvantages. In order to compensate them, an APCMR can be used.

This study proposes an APCMR. The proposed device is composed of two or more micro-ring resonators with different diameter. The proposed device is designed using transfer matrix combined with signal flow graph methods. The low crosstalk can be obtained by setting coupling coefficient. The crosstalk of $-10 \mathrm{~dB}$ of the proposed device was calculated for frequency spectral range (FSR) of $100 \mathrm{GHz}$. The detail analysis is presented in this paper.

\section{Device Conviguration}

The basic configuration of the APCMR is shown by Figure 1. APCMR consists of two rings with asymmetric size of the diameter $r_{1}$ and $r_{2}$. The two rings are aligned in a parallel-cascade structure with a distance. The rings are coupled to straight channel optical waveguides with coupling coefficient of $K$.

When a light is coupled to the input port, two light outputs with resonance and anti-resonance effects are induced due to the two MRR in the parallel structure with different size. By adjusting the coupling coefficient between the ring and straight optical 
waveguides, the crosstalk of the proposed device can be controlled.

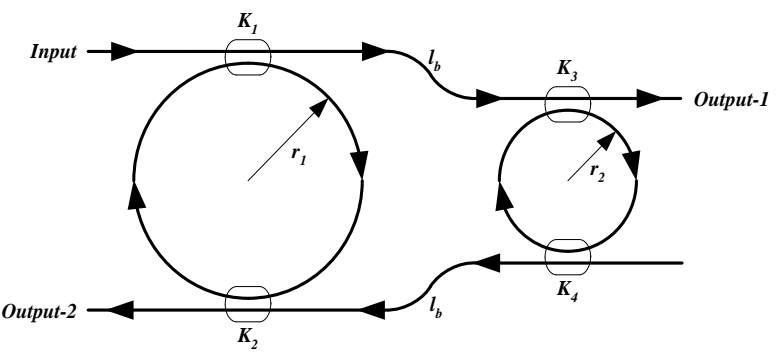

Figure 1. Basic Configuration of APCMR.

\section{Analysis Method :Calculation of APCMR TRANSMITTANCE EQUATION}

The transfer matrix and signal flow-graph methods have been used in the design of multi-path ringresonator (MPRR) [2]. The transfer matrix method is the simplest form of the scattering matrix (in some literatures also referred to as the ABCD transmission matrix or matrix). The signal flow-graph method is used to find the final form of the transfer function of a MRR structure. The signal flow-graph method is simpler than the chain matrix methods [3]. The transfer matrix and signal flow graph can be also used for optical circuits and microwave [4] - [7].

The transfer matrix and signal flow-graph methods have several advantages. The first is easier to analyze the cascade structures (more than one ring), because each ring can be modeled separately. Total transfer matrix can be obtained by multiplying the transfer matrices of each of the rings. Then, the methods do not require complex calculations. The overall structures of the MRR just need to be divided into a network of polar-4 ( 2 inputs and 2 outputs) that can be found by the transfer matrix. Furthermore, the MRR analysis results can be easily simulated using a $\mathrm{C}$ program.

The proposed device was analyzed using the transfer matrix and signal flow-graph methods. The proposed APCMR has two main parameters components, which are a coupling coefficient, $H K_{n}$, and double delay-line value, $G_{d}$, such as shown in Figure 2.

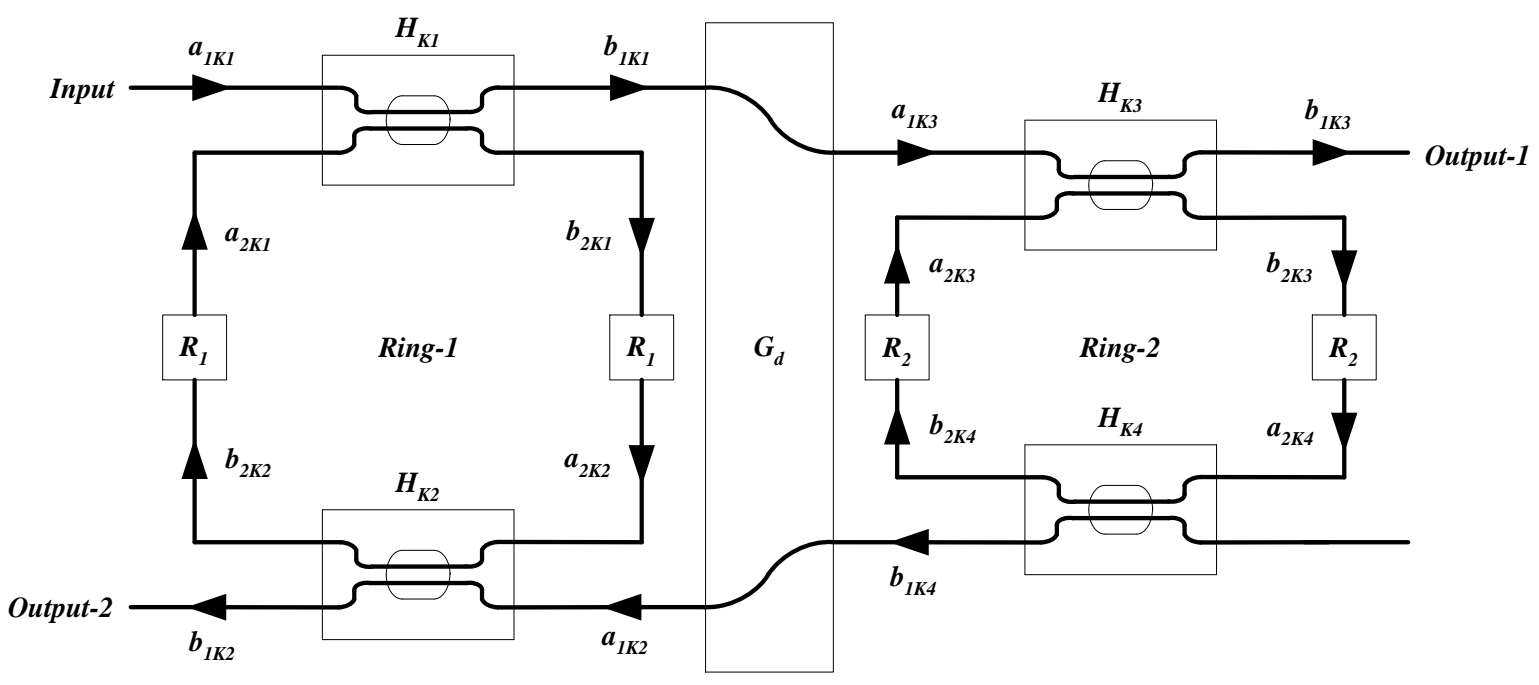

(a)

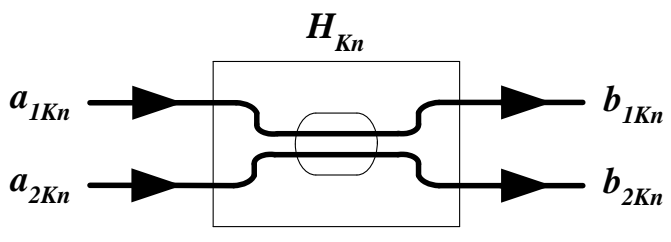

(b)

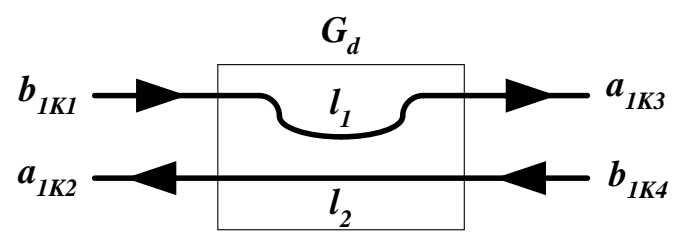

(c)

Figure 2. (a) Block Diagram of the APMCR, (b) the Coupling, and (c) the Double Delay Line. 
Transfer matrices of the coupling and double delay-line are expressed as

$$
\begin{aligned}
& {\left[H_{K n}\right]=\sqrt{1-\gamma}\left[\begin{array}{cc}
\sqrt{1-K_{n}} & -j \sqrt{K_{n}} \\
-j \sqrt{K_{n}} & \sqrt{1-K_{n}}
\end{array}\right]=\left[\begin{array}{cc}
A_{n} & B_{n} \\
C_{n} & D_{n}
\end{array}\right],} \\
& {\left[G_{d}\right]=\left[\begin{array}{cc}
e^{j(\beta-j \alpha) l_{b}} & 0 \\
0 & e^{-j(\beta-j \alpha) l_{b}}
\end{array}\right],} \\
& \left.\begin{array}{c}
R_{n}=e^{-j(\beta-j \alpha) \pi r} \\
\text { where, } \quad n=1,2,3, \ldots, \mathrm{n}
\end{array}\right\}
\end{aligned}
$$

$\gamma$ is the coupling loss, $\beta$ is the propagation constant, and $\alpha$ is the attenuation coefficient. Same coupling loss and propagation constant are assumed. Therefore, the transfer matrix of each coupling and double delay-line are expressed in following equation, respectively,

$$
\begin{aligned}
& {\left[\begin{array}{l}
b_{1 K n} \\
b_{2 K n}
\end{array}\right]=\left[\begin{array}{ll}
A_{1} & B_{1} \\
C_{1} & D_{1}
\end{array}\right]\left[\begin{array}{l}
a_{1 K n} \\
a_{2 K n}
\end{array}\right],} \\
& {\left[\begin{array}{l}
b_{1 K 1} \\
b_{2 K 2}
\end{array}\right]=\left[G_{d}\right]\left[\begin{array}{l}
a_{1 K 3} \\
a_{2 K 4}
\end{array}\right] \text {, }}
\end{aligned}
$$

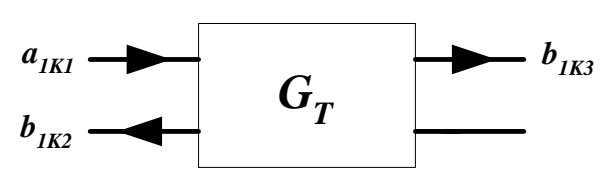

Figure 3. Model of the Proposed APCMR.

From Figure 2 (a) it can be seen that the input APCMR is a $a_{1 K 1}$ while output- 1 and output- 2 is $b_{1 K 3}$ and $b_{1 K 2}$ so that APCMR can be modeled as Figure 3. Therefore, the proposed APCMR can be modeled as shown in Figure 3. As a result, the transfer matrix becomes

$$
\left[\begin{array}{l}
a_{1 K 1} \\
b_{1 K 2}
\end{array}\right]=\left[G_{T}\right]\left[\begin{array}{c}
b_{1 K 3} \\
0
\end{array}\right]=\left[\begin{array}{ll}
\left(G_{T}\right)_{11} & \left(G_{T}\right)_{12} \\
\left(G_{T}\right)_{21} & \left(G_{T}\right)_{22}
\end{array}\right]\left[\begin{array}{c}
b_{1 K 3} \\
0
\end{array}\right] .
$$

Matrix $\left[G_{T}\right]$ is the transfer matrix for the feedbackward configuration, while feed-forward configuration for the APCMR as expressed as:

$$
\left[\begin{array}{l}
b_{1 K 3} \\
b_{1 K 2}
\end{array}\right]=\left[H_{T}\left[\begin{array}{c}
a_{1 K 2} \\
0
\end{array}\right]=\left[\begin{array}{ll}
\left(H_{T}\right)_{11} & \left(H_{T}\right)_{12} \\
\left(H_{T}\right)_{21} & \left(H_{T}\right)_{22}
\end{array}\right]\left[\begin{array}{c}
a_{1 K 2} \\
0
\end{array}\right] .\right.
$$

Figure 4. Model of the Ring-1 and 2.

Matrix $\left[G_{T}\right]$ can be obtained by the multiplication between transfer matrices of each ring and double delay-line. The transfer matrices of the ring- 1 and 2 are $\left[G_{1}\right]$ and $\left[G_{2}\right]$, respectively, where the diagram blocks of them are shown in Figure 4. Based on Figure 2 (b), the proposed APCMR input is $a_{1 K 1}$ while the outputs are defined as $b_{1 K 3}$ and $b_{1 K 2}$, the transfer matrix can be expressed as

$$
\left[\begin{array}{l}
a_{1 K 1} \\
b_{1 K 2}
\end{array}\right]=\left[G_{d}\right]\left[G_{1}\right]\left[G_{2}\right]\left[\begin{array}{c}
b_{1 K 3} \\
0
\end{array}\right] .
$$

Then the transmittance of two light outputs between the anti-resonance $\left(T_{a r}\right)$ and resonance output $\left(T_{r}\right)$ can be transformed as following equations by considering Equations (7) and (8)

$$
\begin{gathered}
T_{a r}=\left|\frac{b_{1 K 3}}{a_{1 K 1}}\right|^{2}=\left|\left(H_{T}\right)_{11}\right|^{2}, \\
T_{r}=\left|\frac{b_{1 K 2}}{a_{1 K 1}}\right|^{2}=\left|\left(H_{T}\right)_{21}\right|^{2} .
\end{gathered}
$$

The $\left[G_{1}\right]$ and $\left[G_{2}\right]$ are the transfer matrices of feed forward from matrices $\left[H_{1}\right]$ and $\left[H_{2}\right]$ for ring-1 and 2 . The elements of the transfer function $\left(H_{11}, H_{12}, H_{21}\right.$, and $H_{22}$ ), which a function of $K_{\mathrm{i}}, K_{2}$, and $K_{3}$, can be derived by using signal flow chart.

After transmittance equations for anti-resonance output and resonance output was obtained, to determined the frequency response of APCMR was used computer simulations.C program in compiler with Cygwin is used to implement the calculation of transmittance. These figures are the results of computer simulation calculations described (on-plot) using the program gnuplot version 3.7 which will produce a frequency response of APCMR.

\section{RESUlt AND Discusion}

In order to obtain the values of parameters (crosstalk, bandwidth, and ripple ratio) of APCMR proposed, the value of the variable coupling coefficient can be adjusted $\left(K_{1}, K_{2}, K_{3}\right.$, dan $\left.K_{4}\right)$. Through comparing the values of these parameters, the optimum design of APCMR is achived. The optimum design is expected to have $\leq-20 \mathrm{~dB}$ crosstalk, wide bandwidth, and ripple ratio $\leq 1 \mathrm{~dB}$. We assume that the FSR is set to $100 \mathrm{GHz}$, which is sufficient FSR. Several configurations based on different of the coupling coefficient are used for simulation parameters, as follow,

1. $K_{1}=K_{2}=K_{3}=K_{4}$, where $K_{l}=K_{2}=K_{3}=K_{4}=0.01-0.7$.

2. $K_{1} \neq K_{2}=K_{3}=K_{4}$, where $K_{1}=0.01-0.7$; and $K_{2}=K_{3}=K_{4}=0.01$, $0.05,0.1,0.2,0.3,0.4,0.5,0.6,0.7$.

3. $K_{1}=K_{2} \neq K_{3}=K_{4}$, where $K_{l}=K_{2}=0.01-0.7$; and $K_{3}=K_{4}=0.01$, $0.05,0.1,0.2,0.3,0.4,0.5,0.6,0.7$.

4. $K_{1}=K_{3} \neq K_{2}=K_{4}$, where $K_{1}=K_{3}=0.01-0.7$; and $K_{2}=K_{4}=0.01$, $0.05,0.1,0.2,0.3,0.4,0.5,0.6,0.7$.

5. $K_{1} \neq K_{2} \neq K_{3}=K_{4}$, where $\mathrm{K}_{1}=0.01,0.05,0.1,0.2,0.3,0.4,0.5,0.6$, $0.7 ; \mathrm{K}_{2}=0.01,0.1,0.3,0.5$, and 0.7 ; and $\mathrm{K}_{3}=\mathrm{K}_{4}=0.01-0.7$.

By calculating the crosstalk of the proposed APCMR at the FSR of $100 \mathrm{GHz}$ for each configuration, then optimum design of the proposed device can be obtained. 


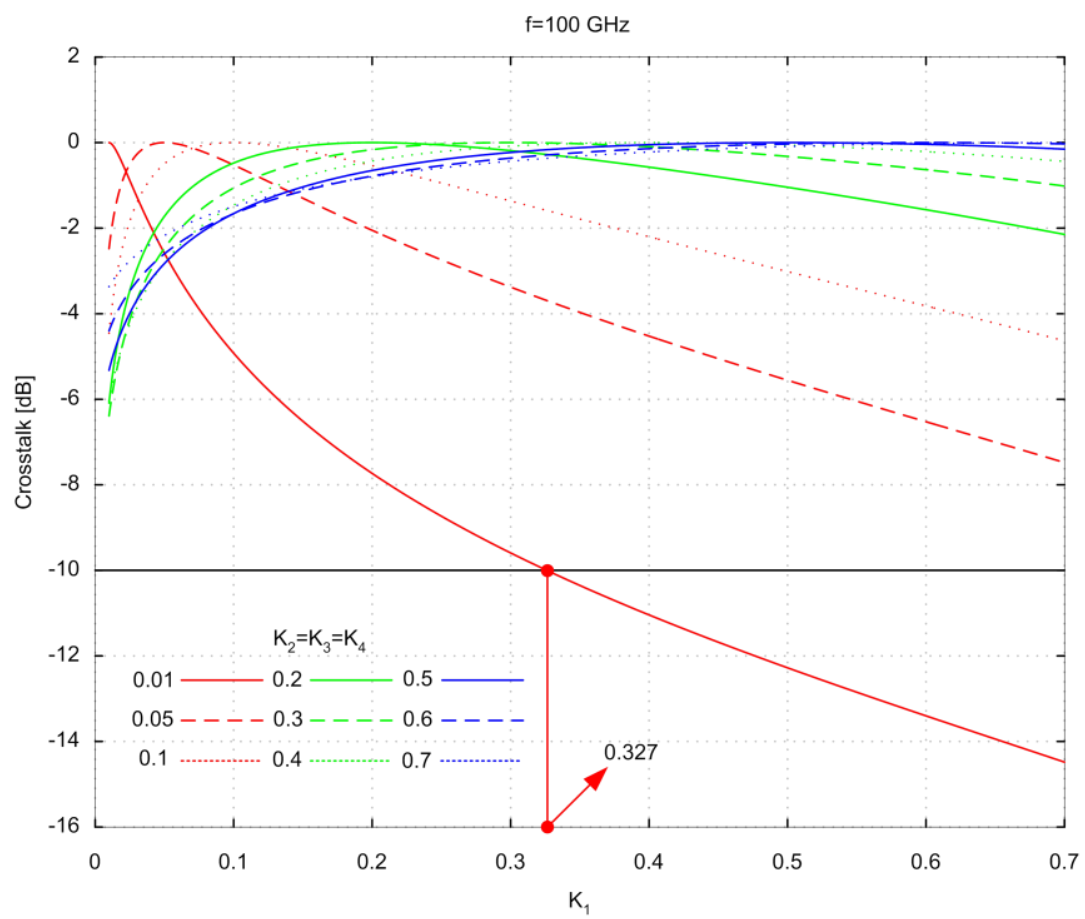

Figure 5. Calculated Crosstalk of the Proposed APCMR for Several Values of $K_{1}$.

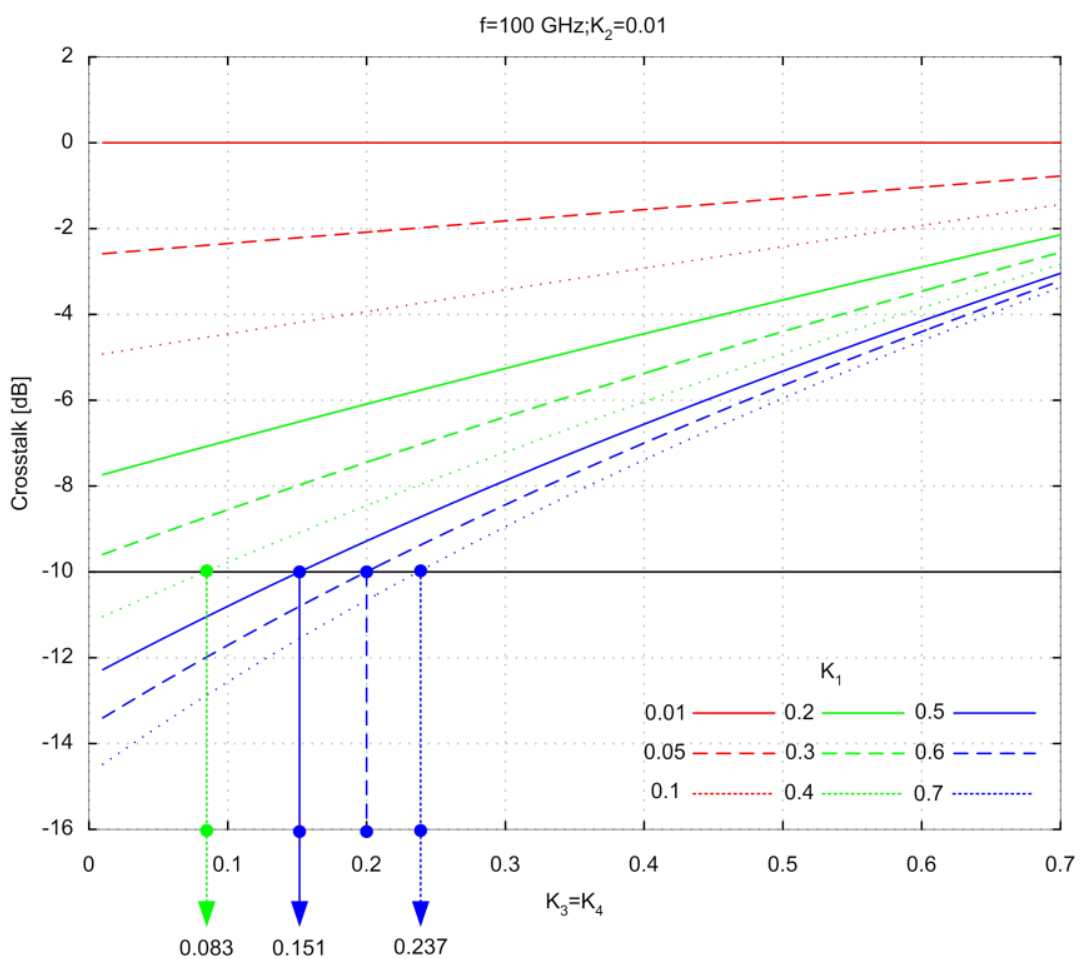

Figure 6. Calculated Crosstalk of the Proposed APCMR for Several Values of the $K_{3}=K_{4}$.

Using computer simulation of the configuration 1 and 3 , the crosstalk of $0 \mathrm{~dB}$ can be obtained. By using the configuration 4, the same value of crosstalk of below $0 \mathrm{~dB}$ can be obtained for frequency of $100 \mathrm{GHz}$, however the peak of the spectrum on this configuration is under $0 \mathrm{~dB}$ due to the power loss on the ring, even $\alpha=0 \mathrm{~dB} / \mathrm{cm}$. Therefore, it will be used configuration 2 and 5 to determine the optimum design of APCMR.
In order to determine the optimum device design of the proposed APCMR, we selected the configurations of 2 and 5. The calculated crosstalk as function to the coupling coefficients for configuration 2 and 5 are shown in Figure 5 and 6 , respectively. We can see that the calculated crosstalk was over $-20 \mathrm{~dB}$, therefore the crosstalk of $-10 \mathrm{~dB}$ was selected for optimization. The optimized parameters for obtaining crosstalk of $-10 \mathrm{~dB}$ at $100 \mathrm{GHz}$ FSR were calculated as follow: $K_{1}=0.7, K_{2}$ $=0.01$, and $K_{3}=K_{4}=0.237$. 


\section{CONCLUSION}

We have proposed an APCMR for optical filter. The proposed device was analyzed using transfer matrix and signal flow graph methods. The optimization of the proposed device was done with crosstalk of $-10 \mathrm{~dB}$ at FSR 100G Hz. The low crosstalk value can be obtained by adjusting the coupling coefficients. The proposed device can be used for optical filters and sensors.

\section{REFERENCES}

[1] S. V. Kartalopoulos, Introduction to DWDM Technology : Data in Rainbow, Lucent Technologies, 2000

[2] I. S. Hidayat, "A Study on Optical Micro-ring Resonator for Optical Wavelength Filter", Graduation dissertation, School of
Natural Scienece and Technology Okayama University, 2003.

[3] S. C. Hagness, "FDTD Computational Electromagnetics Modelling of Microcavity Lasers and Resonant Optical Structures", Graduation dissertation doctor of philosophy in electrical engineering, Northwestern University Evanston Illinois, 1998

[4] N. Kashima, Passive Optical Components for Optical Fiber Transmission, Artech House, 1995.

[5] J. K. S. Poon, J. Scheuer, S. Mookherjea, G. T. Paloczi, Y. Huang, and A. Yariv, "Matrix analysis of micro-ring coupledresonator optical waveguides", Optics Express, vol. 12, no. 1, Jan. 2004.

[6] F. Sanchez, "Matrix algebra for all-fiber optical resonators", IEEE Journal of Lightwave Technology, vol. 9, no. 7, Jul. 1991.

[7] D. M. Pozar, Microwave Engineering, John Wiley \& Sons, 2003. 